\title{
Invited Editorial \\ Potential Strategies to Improve Antimicrobial Utilisation in Hospitals in Bangladesh Building on Experiences Across Developing Countries Mainul Haque ${ }^{1}$,Brian Godman ${ }^{2}$
}

Keywords Antimicrobial resistance; Antimicrobial stewardship programmes; Bangladesh; Hospitals; Point Prevalence studies; surgical site infections.

Bangladesh Journal of Medical Science Vol. 19 No. 03 July'20. Page : 469-477 DOI: https://doi.org/10.3329/bjms.v20i3.52787

Antimicrobial resistance (AMR) is a growing problem worldwide, leading to increased morbidity, mortality and $\operatorname{costs}^{1-6}$, with the overall costs of AMR typically exceeding the costs of the different antibiotics prescribed and dispensed ${ }^{7}$. AMR is particularly important in lower- and middle-income countries (LMICs) as these countries have the highest burden of infectious diseases with growing rates of resistant organisms $^{8-12}$. The concerns with AMR have resulted in multiple initiatives internationally, regionally and nationally, to reduce resistance rates, which include country specific National Action Plans (NAPs) ${ }^{13-17}$. Bangladesh is no exception with its NAP launched in $2017^{18}$. The Global Antibiotic Resistance Partnership (GARP)-Bangladesh national working group report, published in 2018, also identified a number of activities that should be undertaken in Bangladesh to address concerns with inappropriate utilization of antimicrobials resulting in high resistance rates to commonly prescribed antibiotics and organisms including amoxycillin, cloxacillin, carbapenem, ceftriaxone, and metronidazole as well as $S$. pneumonia $^{8,19}$. Issues to address include high rates of inappropriate prescribing of antimicrobials in both hospitals and ambulatory care, with self-purchasing of antibiotics also common in Bangladesh ${ }^{820-24}$. Selfpurchasing is enhanced among village pharmacies in rural areas of Bangladesh, and wider, as community pharmacists are a trusted source for information. The high co-payments for care in Bangladesh, which can be catastrophic for some families when members become ill ${ }^{25,26}$, can also be reduced by avoiding physician payments. Alongside this, community pharmacies are often more convenient for patients as they are typically open longer hours than primary healthcare clinics. Figure 1 consolidates these different strands to highlight why addressing AMR is a key priority in Bangladesh and across countries, and why both sectors are important going forward.

In this editorial, we will just concentrate on potential programmes to improve antimicrobial use in hospitals. This builds on recent publications on potential ways to tackle AMR in Bangladesh, and more broadly among LMICs, to stimulate future debates $^{19,27}$. This is because we are aware that there can be concerns regarding the extent of antimicrobial stewardship programmes (ASPs) and other activities among hospitals in Bangladesh, acknowledging that ASPs are more difficult to introduce in LMICs due to manpower and cultural issues ${ }^{8,10,27-32}$. In addition,

1. Mainul Haque, Unit of Pharmacology, Faculty of Medicine and Defence Health, Universiti Pertahanan Nasional Malaysia (National Defence University of Malaysia), Kem Perdana Sungai Besi, 57000 Kuala Lumpur, Malaysia. Orcid ID: https://orcid.org/0000-0002-6124-7993

2. Brian Godman, Strathclyde Institute of Pharmacy and Biomedical Sciences, University of Strathclyde, Glasgow G4 0RE, United Kingdom. Orcid ID: https://orcid.org/0000-0001-6539-6972 \& Division of Public Health Pharmacy and Management, School of Pharmacy, Sefako Makgatho Health Sciences University, Pretoria, South Africa. \& School of Pharmaceutical Sciences, Universiti Sains Malaysia, Penang, Malaysia

Correspondence to: Brian Godman, Strathclyde Institute of Pharmacy and Biomedical Sciences, University of Strathclyde, Glasgow G4 0RE, United Kingdom. Email: Brian.Godman@strath.ac.uk . 


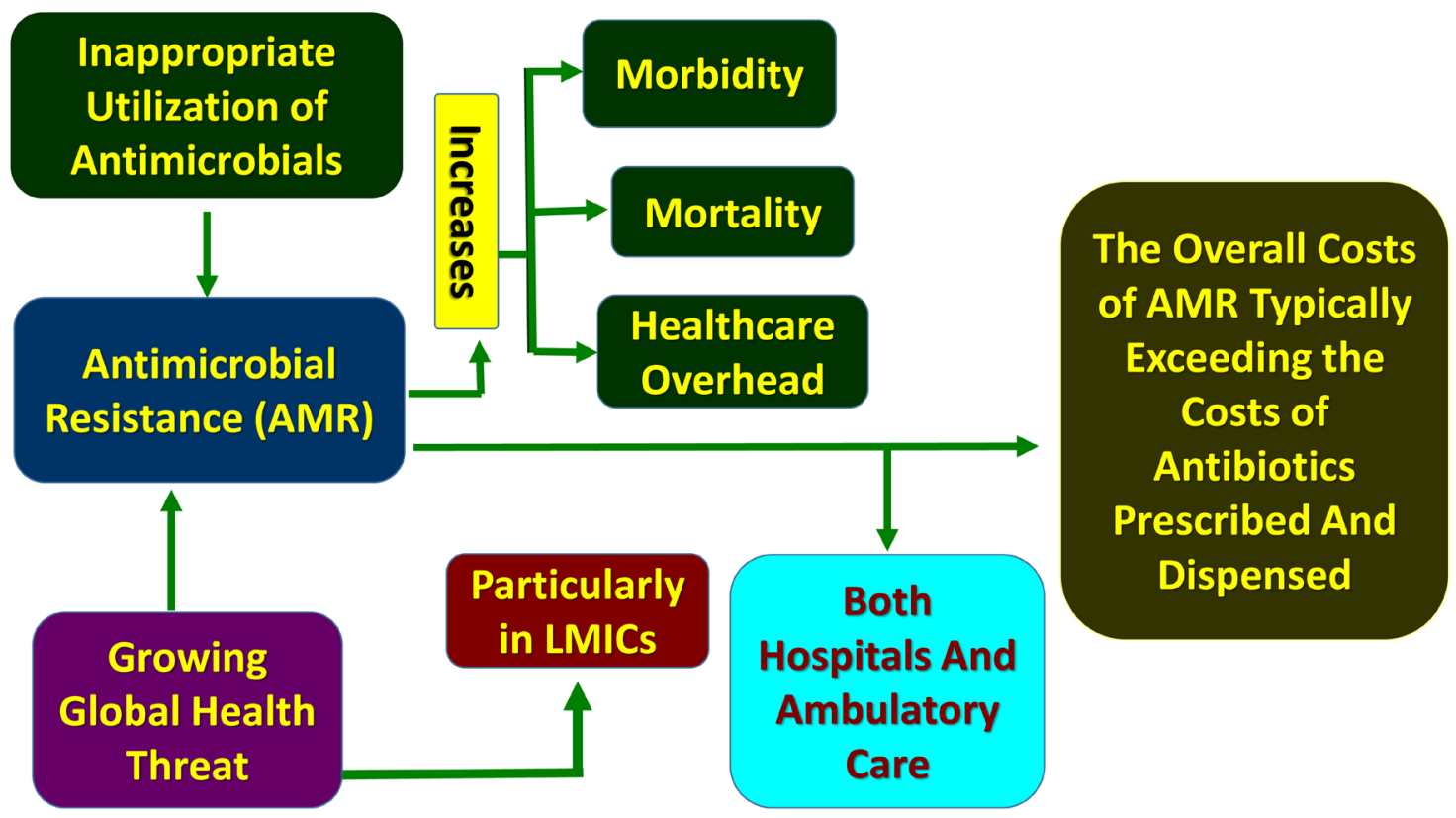

Figure 1: Key Issues Associated with Rising Antimicrobial Resistance.

there can be multiple prescribing of antibiotics to patients in hospitals in Bangladesh, which can often be inappropriate ${ }^{8}$. Alongside this, hospital physicians in LMICs often gain their knowledge about antimicrobials from pharmaceutical companies, and are influenced by them ${ }^{33-37}$, with physicians in Bangladesh no exception ${ }^{38,39}$. There can also be limited knowledge regarding ASPs among physicians in LMICs versus higher-income countries $^{40-42}$, building on variable knowledge generally regarding antibiotics among healthcare workers and students in LMICs including Bangladesh ${ }^{43-46}$. Consequently, this first editorial of two will just concentrate on potential ways to improve antibiotic prescribing in hospitals.

The first step to improve antibiotic utilization in hospitals is to gain a good understanding of current utilization patterns ${ }^{19}$. This includes undertaking point prevalence surveys (PPS) within hospitals, which help document current antimicrobial use among in-patients. The Global PPS studies are the most well-known surveys, which do include hospitals from across $\mathrm{Asia}^{47}$. More recently, Saleem et al. (2020) undertook a systematic review of PPS studies globally, including Asia, and found that antimicrobial use was appreciably higher in non-European versus European hospitals which is a concern ${ }^{48}$. Undertaking such PPS studies can identify key areas for future quality improvement programmes within hospitals $s^{47,49-51}$. Key areas can include addressing the extent of hospital acquired infections (HAIs) with their implications for increasing length of stay and costs ${ }^{52-56}$. Alongside this, addressing the extent of inadequate physician documentation in patients' notes where this exists including the rationale for any antibiotic prescriptions, the lack of regular reviews of antibiotic usage including IV to oral switches, issues with the timing and length of antibiotic usage to reduce surgical site infections (SSIs) as well as concerns generally with adherence to local, regional or national antibiotic guidelines ${ }^{49,50,57-59}$.

A key area to start with in hospitals to reduce inappropriate use of antibiotics is their prescribing to prevent SSIs ${ }^{60}$. This is because SSIs are currently the most common infectious complications seen among hospitalized patients in $\mathrm{LMICs}^{61,62}$, early antibiotic administration has limited effectiveness, and prolonged administration after the operation increases AMR and adverse reactions without reducing SSI rates ${ }^{63-65}$. Despite this, inappropriate use of antibiotics to prevent SSIs is common among LMICs $^{63}$. Several studies have now shown that appropriate educational activities accompanied by policies, guidelines and targets, as well as monitoring subsequent prescribing activities, can appreciably reduce inappropriate antibiotic prescribing and costs associated with SSIs among a range of $\mathrm{LMICs}^{63}$. As a result, providing guidance to hospitals in Bangladesh seeking to enhance their prescribing of antimicrobials to prevent SSIs as part of generally reducing HAIs. 
Adherence to agreed guidelines is also increasingly seen as an important marker of the quality of antibiotic prescribing within hospitals ${ }^{47,58,66-68}$. However, guidelines must be readily available, updated, easyto-use and trusted to enhance their use in practice ${ }^{69-71}$. In addition, based on local antibiograms to improve empiric antibiotic prescribing whilst waiting for culture and sensitivity results ${ }^{56,72}$. Other quality indicators can centre around the AWaRe list of antibiotics, documentation and review rates, and early switching to oral antibiotics where pertinent ${ }^{59,73-77}$. However, any quality indicators developed must be easy to implement, measurable and agreed by all key stakeholders to enhance their use and impact ${ }^{78,79}$.
All these initiatives can be part of ASPs within hospitals, and included within the remit of infection, prevention and control groups within hospitals ${ }^{80.81}$. Alternatively, part of the remit of Drug and Therapeutic Committees (DTC) ${ }^{19}$. The introduction of ASPs within hospitals has appreciably reduced inappropriate antibiotic use and costs ${ }^{10,67,82-85}$. In their recent review, Majumder et al. (2020) discussed the nine core elements of any ASP, and how they align with the ten essential services of public health, endorsed within the Bangladesh NAP and the GARP-Bangladesh National Working Group ${ }^{10,18,19}$ (Figure 2). A critical element of any ASP is a shared responsibility among all key stakeholders within a hospital ${ }^{10}$.

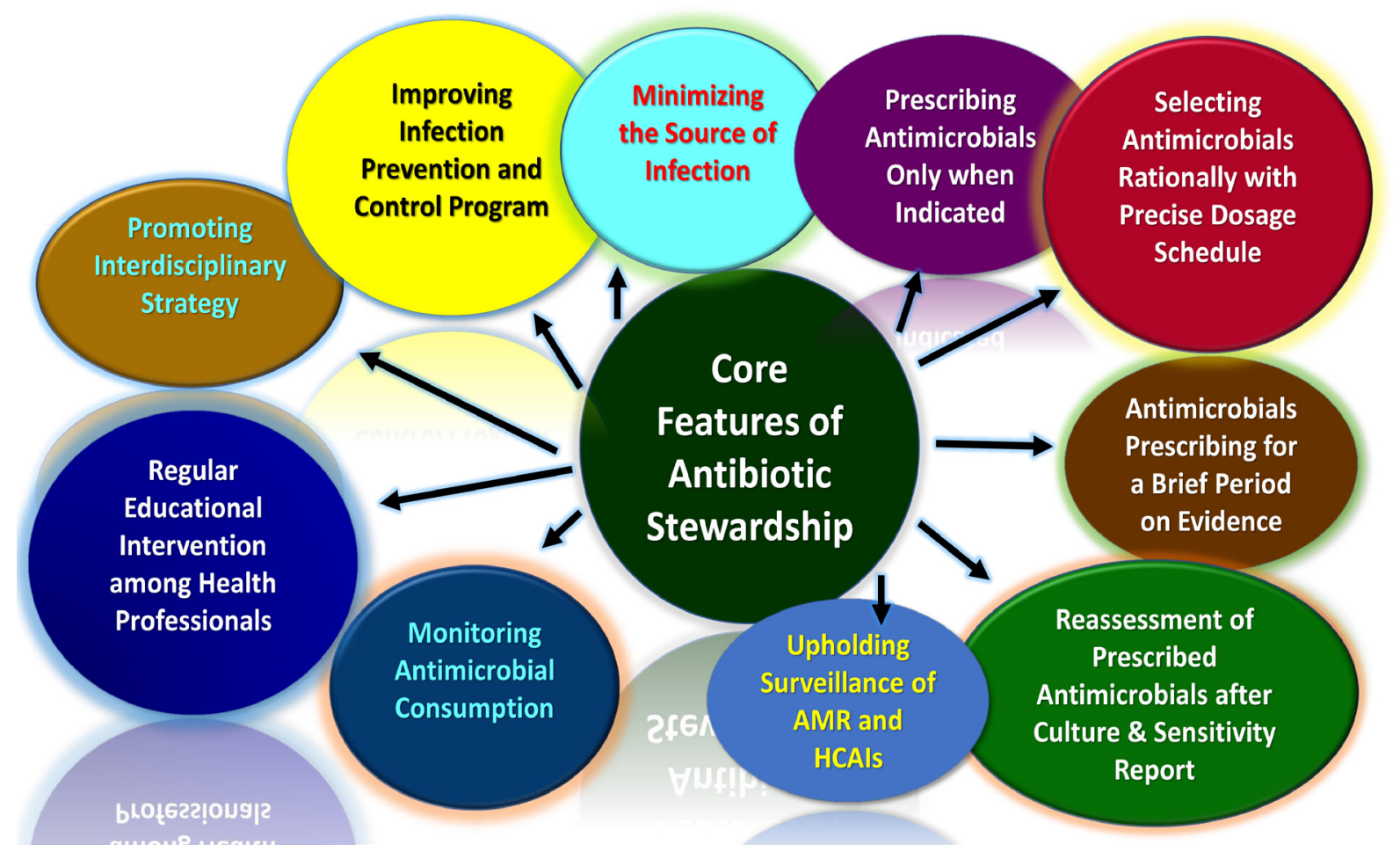

Figure 2: Core Elements of Any Antimicrobial Stewardship Program [Adapted from Majumder et al ${ }^{10}$ ]. HCAIs $=$ Health Care Associated Infections

Researchers in LMICs are starting to assess adherence to national strategies in hospital facilties to further reduce AMR rates ${ }^{86}$, and we see this continuing. Clinical pharmacists in hospitals can also play key educational and orchestrational roles driving forward ASPs as part of DTC and other activities ${ }^{29,87}$. They can also co-ordinate therapeutic interchange polices to select potential replacement antibiotics if there are shortages, which are occuring more often with supply and other problems ${ }^{88,89}$. However, this will require more intensive training on clinical pharmacy and antimicrobials as part of undergraduate courses and post qualification. This has been a conern with pharmacy education in Bangladesh typically industry based with an appreciable proportion of the BPharm curriculum focusing on pharmaceutical science and industry-based courses rather than clinical issues including AMR. However, this is beginning to change, and can build on models for good pharmacy management in the community ${ }^{90,91}$.

In conclusion, it is important that all key stakeholders work together in hospitals in Bangladesh to improve 
future antibiotic utilisation and reduce AMR, which is in line with the NAP and GARP-Bangladesh National Working Group ${ }^{18,19}$. This is key to reducing future morbidity, mortality and costs assicated with AMR. We have witnessed the catastrophic consequences of COVID 19 arising from misinformation regarding hydroxychloroquine and antibiotics, increasing costs and mortality with no subsequent patient benefit despite the initial hype ${ }^{22,92-96}$. In addition, concerns with treatments such as remdesivir and lopinavir/ ritonavir being proposed without a solid evidence- base, which also showed little benefit in reality in well-constructed clinical trials ${ }^{92,97,98}$. Consequently, it is important that key stakeholders work together in an evidence-based environment to introduce well proven activities to improve future antibiotic utilisation within their hospitals, and continually monitor their outcome to reduce AMR. Alongside this, work together to address misinformation and its consequences. This is the only proven way to reduce AMR rates in hospitals in Bangladesh. We will be looking to monitor such activities in future.

\section{References:}

1. Zhen X, Lundborg CS, Sun X, Hu X, Dong H. Economic burden of antibiotic resistance in ESKAPE organisms: a systematic review. Antimicrob Resist Infect Control. 2019;8:137. Doi: 10.1186/s13756-019-0590-7.

2. Cassini A, Hogberg LD, Plachouras D, Quattrocchi A, Hoxha A, Simonsen GS, et al. Attributable deaths and disability-adjusted life-years caused by infections with antibiotic-resistant bacteria in the EU and the European Economic Area in 2015: a population-level modelling analysis. The Lancet Infectious Diseases. 2019;19(1):5666. Doi: 10.1016/S1473-3099(18)30605-4

3. Hofer U. The cost of antimicrobial resistance. Nature reviews Microbiology. 2019;17(1):3. Doi: 10.1038/ s41579-018-0125-x

4. Morel CM, Alm RA, Årdal C, Bandera A, Bruno GM, Carrara E, et al. A one health framework to estimate the cost of antimicrobial resistance. Antimicrobial Resistance \& Infection Control. 2020;9(1):187. Doi:

\section{$10.1186 / \mathrm{s} 13756-020-00822-6$}

5. Dadgostar P. Antimicrobial Resistance: Implications and Costs. Infection and Drug Resistance. 2019;12:3903-10. Doi: $10.2147 /$ IDR.S234610

6. Jiang T, Chen XS. Outcome Impacts Due to PathogenSpecific Antimicrobial Resistance: A Narrative Review of Published Literature. Int J Environ Res Public Health. 2020;17(4). Doi: 10.3390/ijerph17041395

7. Shrestha P, Cooper BS, Coast J, Oppong R, Do Thi Thuy N, Phodha T, et al. Enumerating the economic cost of antimicrobial resistance per antibiotic consumed to inform the evaluation of interventions affecting their use. Antimicrobial Resistance \& Infection Control. 2018;7(1):98. Doi: 10.1186/s13756-018-0384-3

8. Hoque R, Ahmed SM, Naher N, Islam MA, Rousham $\mathrm{EK}$, Islam BZ, et al. Tackling antimicrobial resistance in Bangladesh: A scoping review of policy and practice in human, animal and environment sectors. PloS One. 2020;15(1):e0227947. Doi: 10.1371/journal. 
pone. 0227947

9. Ahmed I, Rabbi Md. B, Sultana S. Antibiotic resistance in Bangladesh: A systematic review. International Journal of Infectious Diseases. 2019; 80: 54-61. Doi: 10.1016/j.ijid.2018.12.017

10. Majumder MAA, Rahman S, Cohall D, Bharatha A, Singh K, Haque M, et al. Antimicrobial Stewardship: Fighting Antimicrobial Resistance and Protecting Global Public Health. Infection and Drug Resistance. 2020;13:4713-38. Doi: 10.2147/IDR.S290835

11. Ayukekbong JA, Ntemgwa M, Atabe AN. The threat of antimicrobial resistance in developing countries: causes and control strategies. Antimicrobial Resistance \& Infection Control. 2017;6(1):47. Doi: 10.1186/s13756017-0208-X

12. Sartelli M, Labricciosa FM, Barbadoro P, Pagani L, Ansaloni L, Brink AJ, et al. The Global Alliance for Infections in Surgery: defining a model for antimicrobial stewardship-results from an international crosssectional survey. World Journal of Emergency Surgery. 2017;12:34. Doi: 10.1186/s13017-017-0145-2

13. WHO. Technical Series on Primary Health Care. Antimicrobial resistance and primary health care. 2018. Available at URL: https://www.who.int/docs/ default-source/primary-health-care-conference/amr. pdf?sfvrsn=8817d5ba_2. (Accessed 25 February 2021)

14. WHO. Global Action Plan On Antimicrobial Resistance. 2015. Available at URL: https://apps.who.int/iris/ bitstream/handle/10665/193736/9789241509763_eng. pdf? sequence $=1$. (Accessed 25 February 2021)

15. Laxminarayan R, Van Boeckel T, Frost I, Kariuki S, Khan EA, Limmathurotsakul D, et al. The Lancet Infectious Diseases Commission on antimicrobial resistance: 6 years later. The Lancet Infectious Diseases. 2020;20(4):e51-e60. Doi: 10.1016/S14733099(20)30003-7

16. IACG. No Time To Wait: Securing The Future From Drug-Resistant Infections. Report To The SecretaryGeneral Of The United Nations. April 2019. Available at URL: https://www.who.int/antimicrobial-resistance/ interagency-coordination-group/IACG_final_report_ EN.pdf. (Accessed 25 February 2021)

17. Saleem Z, Hassali MA, Hashmi FK. Pakistan's national action plan for antimicrobial resistance: translating ideas into reality. The Lancet Infectious Diseases. 2018;18(10):1066-7. Doi: 10.1016/S14733099(18)30516-4

18. Ministry of Health and Family Welfare (MoHFW), Government of Bangladesh. National Action Plan: Antimicrobial Resistance Containment in Bangladesh 2017-'22. 2017. Available from URL: https://www.flemingfund.org/wp-content/uploads/ d3379eafad36f597500cb07c21771ae3.pdf. (Accessed
25 February 2021)

19. Global Antibiotic Resistance Partnership - Bangladesh, GARP-Bangladesh National Working Group. Antibiotic Use and Resistance in Bangladesh - Situational Analysis and Recommendations. 2018. Available at URL: https:// cddep.org/wp-content/uploads/2018/08/ANTIBIOTICUSE-RESISTANCE-IN-BD_2018.pdf. (Accessed 25 February 2021)

20. Biswas M, Roy MN, Manik MI, Hossain MS, Tapu SM, Moniruzzaman M, et al. Self medicated antibiotics in Bangladesh: a cross-sectional health survey conducted in the Rajshahi City. BMC Public Health. 2014;14:847. Doi: 10.1186/1471-2458-14-847

21. Uzzal M, Anup K, Abdul S, Anwar U. Prevalence, Practice and Irrationality of Self-medicated Antibiotics among People in Northern and Southern Region of Bangladesh. International Journal of Research in Pharmacy and Biosciences. 2017; 4 (10): 17-24.

22. Haque M, Islam S, Iqbal S, Urmi UL, Kamal ZM, Shuvo SA et al. Availability and price changes of potential medicines and equipment for the prevention and treatment of COVID-19 among pharmacy and drug stores in Bangladesh; findings and implications. Bangladesh Journal of Medical Science. 2020; 19 (Special Issue on COVID-19): S36-S50. Doi:10.3329/ bjms.v19i0.48106

23. Rousham EK, Islam MA, Nahar P, Lucas PJ, Naher $\mathrm{N}$, Ahmed SM, et al. Pathways of antibiotic use in Bangladesh: qualitative protocol for the PAUSE study. BMJ Open. 2019;9(1):e028215. doi.10. 1136/ bmjopen2018-028215

24. Rashid MM, Chisti MJ, Akter D, Sarkar M, Chowdhury F. Antibiotic use for pneumonia among children underfive at a pediatric hospital in Dhaka city, Bangladesh. Patient Preference and Adherence. 2017;11:1335-42. Doi: 10.2147/PPA.S140002

25. Chowdhury M, Stewart Williams J, Wertheim H, Khan WA, Matin A, Kinsman J. Rural community perceptions of antibiotic access and understanding of antimicrobial resistance: qualitative evidence from the Health and Demographic Surveillance System site in Matlab, Bangladesh.GlobHealthAction.2019;12(sup1):1824383. Doi: 10.1080/16549716.2020.1824383

26. Khan JAM, Ahmed S, Evans TG. Catastrophic healthcare expenditure and poverty related to out-of-pocket payments for healthcare in Bangladesh-an estimation of financial risk protection of universal health coverage. Health Policy Plan. 2017;32(8):1102-10. Doi: 10.1093/ heapol/czx048

27. Yusuf DMA. Antimicrobial Stewardship: Bangladesh Perspective. Bangladesh Journal of Infectious Diseases. 2018;5:1. Doi:10.3329/bjid.v5i1.37708

28. Hijazi K, Joshi C, Gould IM. Challenges and 
opportunities for antimicrobial stewardship in resourcerich and resource-limited countries. Expert review of Anti-Infective Therapy. 2019;17(8):621-34. Doi: 10.1080/14787210.2019.1640602

29. Gauthier TP. Antimicrobial Stewardship In Bangladesh: A Pharmacist's Perspective. 2020. Available at URL: https://www.idstewardship.com/antimicrobialstewardship-bangladesh-pharmacists-perspective/. (Accessed 25 February 2021)

30. Cox JA, Vlieghe E, Mendelson M, Wertheim H, Ndegwa L, Villegas MV, et al. Antibiotic stewardship in lowand middle-income countries: the same but different? Clinical Microbiology and Infection. 2017;23(11):8128. Doi: 10.1016/j.cmi.2017.07.010

31. Akpan MR, Isemin NU, Udoh AE, Ashiru-Oredope D. Implementation of antimicrobial stewardship programmes in African countries: a systematic literature review. Journal of Global Antimicrobial Resistance. 2020; 22:317-324. Doi: 10.1016/j.jgar.2020.03.009

32. Kakkar AK, Shafiq N, Singh G, Ray P, Gautam V, Agarwal R, et al. Antimicrobial Stewardship Programs in Resource Constrained Environments: Understanding and Addressing the Need of the Systems. Front Public Health. 2020;8:140. Doi: 10.3389/fpubh.2020.00140

33. Ogunleye OO, Fadare JO, Yinka-Ogunleye AF, Anand Paramadhas BD, Godman B. Determinants of antibiotic prescribing among doctors in a Nigerian urban tertiary hospital. Hospital Practice. 2019;47(1):53-8. Doi: 10.1080/21548331.2018.1475997

34. Fadare JO, Oshikoya KA, Ogunleye OO, Desalu OO, Ferrario A, Enwere OO, et al. Drug promotional activities in Nigeria: impact on the prescribing patterns and practices of medical practitioners and the implications. Hospital Practice. 2018;46(2):77-87. Doi: 10.1080/21548331.2018.1437319

35. Mathew P, Ranjalkar J, Chandy SJ. Challenges in Implementing Antimicrobial Stewardship Programmes at Secondary Level Hospitals in India: An Exploratory Study. Front Public Health. 2020;8:493904. Doi: 10.3389/fpubh.2020.493904

36. Khazzaka M. Pharmaceutical marketing strategies' influence on physicians' prescribing pattern in Lebanon: ethics, gifts, and samples. BMC Health Services Research. 2019;19(1):80. Doi: 10.1186/s12913-0193887-6

37. Gul R, Saeed H, Saleem Z, Rasool F, Hashmi FK, Islam $\mathrm{M}$, et al. Perceptions of and barriers to ethical promotion of pharmaceuticals in Pakistan: perspectives of medical representatives and doctors. BMC Medical Ethics. 2021;22(1):2. Doi: 10.1186/s12910-020-00569-0

38. Mohiuddin M, Rashid SF, Shuvro MI, Nahar N, Ahmed SM. Qualitative insights into promotion of pharmaceutical products in Bangladesh: how ethical are the practices? BMC Medical Ethics. 2015;16(1):80. Doi: 10.1186/s12910-015-0075-Z

39. Sharmin R, Sharmin ZR, Md. Mosaddek AS, Islam MZ, Rahman MF, Parvin R, et al. Medicine promotional literature as a source of updated information in Bangladesh: Do those advertising literature promote continued medical education or deceptive advertising? Acta Med Int.2017;4:20-5. Doi: 10.4103/ami.ami_58_17

40. Kalungia AC, Mwambula H, Munkombwe D, Marshall S, Schellack N, May C, et al. Antimicrobial stewardship knowledge and perception among physicians and pharmacists at leading tertiary teaching hospitals in Zambia: implications for future policy and practice. Journal of Chemotherapy. 2019; 31 (7-8): 378-387, Doi: 10.1080/1120009X.2019.1622293

41. Fadare JO, Ogunleye O, Iliyasu G, Adeoti A, Schellack $\mathrm{N}$, Engler D, et al. Status of antimicrobial stewardship programmes in Nigerian tertiary healthcare facilities: Findings and implications. Journal of Global Antimicrobial Resistance. 2019;17:132-6. Doi: 10.1016/j.jgar.2018.11.025

42. Assar A, Abdelraoof MI, Abdel-Maboud M, Shaker $\mathrm{KH}$, Menshawy A, Swelam AH, et al. Knowledge, attitudes, and practices of Egypt's future physicians towards antimicrobial resistance (KAP-AMR study): a multicenter cross-sectional study. Environmental Science and Pollution Research International. 2020;27(17):21292-8. Doi: 10.1007/s11356-020-085345

43. Marzan M, Islam DZ, Lugova H, Krishnapillai A, Haque M, Islam S. Knowledge, Attitudes, and Practices of Antimicrobial Uses and Resistance Among Public University Students in Bangladesh. Infection and Drug Resistance. 2021;14:519-33. Doi: 10.2147/IDR. S289964

44. Firouzabadi D, Mahmoudi L. Knowledge, attitude, and practice of health care workers towards antibiotic resistance and antimicrobial stewardship programmes: A cross-sectional study. J Eval Clin Pract. 2020;26(1):1906. Doi: $10.1111 /$ jep. 13177

45. Haque M, Rahman NAA, McKimm J, Binti Abdullah SL, Islam MZ, Zulkifli Z, et al. A cross-sectional study evaluating the knowledge and beliefs about, and the use of antibiotics amongst Malaysian university students. Expert Review of Anti-Infective Therapy. 2019;17(4):27584. Doi: 10.1080/14787210.2019.1581607.

46. Nisabwe L, Brice $\mathrm{H}$, Umuhire MC, Gwira O, Harelimana JDD, Nzeyimana Z, et al. Knowledge and attitudes towards antibiotic use and resistance among undergraduate healthcare students at University of Rwanda. Journal of Pharmaceutical Policy and Practice. 2020;13(1):7. Doi: 10.1186/s40545-020-00207-5

47. Versporten A, Zarb P, Caniaux I, Gros MF, Drapier $\mathrm{N}$, Miller $\mathrm{M}$, et al. Antimicrobial consumption and 
resistance in adult hospital inpatients in 53 countries: results of an internet-based global point prevalence survey. The Lancet Global Health. 2018;6(6):e619-e29. Doi: 10.1016/S2214-109X(18)30186-4

48. Saleem Z, Hassali MA, Godman B, Versporten A, Hashmi FK, Saeed H, et al. Point Prevalence Surveys of Antimicrobial Use: A Systematic Review And The Implications. Expert Review of Anti-Infective Therapy. 2020. Doi: 10.1080/14787210.2020.1767593

49. Anand Paramadhas BD, Tiroyakgosi C, Mpinda-Joseph P, Morokotso M, Matome M, Sinkala F, et al. Point prevalence study of antimicrobial use among hospitals across Botswana; findings and implications. Expert Review of Anti-Infective Therapy. 2019;17(7):535-46. Doi: 10.1080/14787210.2019.1629288

50. Kurdi A, Hasan AJ, Baker KI, Seaton RA, Ramzi ZS, Sneddon J, et al. A multicentre point prevalence survey of hospital antibiotic prescribing and quality indices in the Kurdistan Regional Government of Northern Iraq: The need for urgent action. Expert Review of Anti-Infective Therapy. 2020. Doi: 10.1080/14787210.2021.1834852

51. Saleem Z, Hassali MA, Versporten A, Godman B, Hashmi FK, Goossens $\mathrm{H}$, et al. A multicenter point prevalence survey of antibiotic use in Punjab, Pakistan: findings and implications. Expert Review of Anti-Infective Therapy. 2019;17(4):285-93. Doi: 10.1080/14787210.2019.1581063

52. Manoukian S, Stewart S, Dancer S, Graves N, Mason $\mathrm{H}, \mathrm{McF}$ arland A, et al. Estimating excess length of stay due to healthcare-associated infections: a systematic review and meta-analysis of statistical methodology. J Hosp Infect. 2018;100(2):222-35. Doi: 10.1016/j. jhin.2018.06.003

53. Irek EO, Amupitan AA, Obadare TO, Aboderin AO. A systematic review of healthcare-associated infections in Africa: An antimicrobial resistance perspective. African Journal of Laboratory Medicine. 2018;7(2):796. Doi: 10.4102/ajlm.v7i2.796

54. Saleem Z, Godman B, Hassali MA, Hashmi FK, Azhar F, Rehman IU. Point prevalence surveys of health-care-associated infections: a systematic review. Pathogens and Global Health. 2019:1-15. Doi: 10.1080/20477724.2019.1632070

55. Saleem Z, Hassali MA, Godman B, Hashmi FK, Saleem F. A multicenter point prevalence survey of healthcareassociated infections in Pakistan: Findings and implications. American Journal of Infection Control. 2019;47(4):421-4. Doi: 10.1016/j.ajic.2018.09.025

56. Nusrat T, Akter N, Rahman NAA, Godman B, DT DR, Haque M. Antibiotic resistance and sensitivity pattern of Metallo- $\beta$-Lactamase Producing Gram-Negative Bacilli in ventilator-associated pneumonia in the intensive care unit of a public medical school hospital in Bangladesh. Hospital Practice. 2020;48(3):128-36. Doi:

\section{$10.1080 / 21548331.2020 .1754687$}

57. Afriyie DK, Amponsah SK, Dogbey J, Agyekum K, Kesse S, Truter I, et al. A pilot study evaluating the prescribing of ceftriaxone in hospitals in Ghana: findings and implications. Hospital Practice. 2017;45(4):143-9. Doi: 10.1080/21548331.2017.1348139

58. Afriyie DK, Sefah IA, Sneddon J, Malcom W, Mckinney R, Cooper L et al. Antimicrobial Point Prevalence Surveys in two Ghanaian hospitals: opportunities for antimicrobial stewardship. JAC Antimicrob Resist. 2020: 1-9. Doi:10.1093/jacamr/dlaa001

59. Dlamini NN, Meyer JC, Kruger D, Kurdi A, Godman B, Schellack N. Feasibility of using point prevalence surveys to assess antimicrobial utilisation in public hospitals in South Africa: a pilot study and implications. Hospital Practice. 2019;47(2):88-95. Doi: 10.1080/21548331.2019.1592880

60. Purba AKR, Setiawan D, Bathoorn E, Postma MJ, Dik J-WH, Friedrich AW. Prevention of Surgical Site Infections: A Systematic Review of Cost Analyses in the Use of Prophylactic Antibiotics. Frontiers in Pharmacology. 2018;9(776). Doi: 10.3389/ fphar.2018.00776

61. Ngaroua, Ngah JE, Benet T, Djibrilla Y. [Incidence of surgical site infections in sub-Saharan Africa: systematic review and meta-analysis - Article in French]. Pan Afr Med J. 2016;24:171. Doi: 10.11604/ pamj.2016.24.171.9754

62. Saito H, Inoue K, Ditai J, Weeks AD. Pattern of PeriOperative Antibiotic Use among Surgical Patients in a Regional Referral and Teaching Hospital in Uganda. Surgical Infections. 2020;21(6):540-6. Doi: 10.1089/ sur.2019.176

63. Mwita JC, Ogunleye O, Olalekan A, Kalungia AC, Kurdi A, Saleem Z, Sneddon J, Godman B. Key Issues Surrounding Appropriate Antibiotic Use for Prevention of Surgical Site Infections in Low- and Middle-Income Countries: A Narrative Review and the Implications. Int J Gen Med. 2021;14:515-530. Doi: 10.2147/IJGM. S253216

64. de Jonge SW, Gans SL, Atema JJ, Solomkin JS, Dellinger PE, Boermeester MA. Timing of preoperative antibiotic prophylaxis in 54,552 patients and the risk of surgical site infection: A systematic review and metaanalysis. Medicine. 2017;96(29):e6903. Doi: 10.1097/ MD.0000000000006903

65. Hawn MT, Knowlton LM. Balancing the Risks and Benefits of Surgical Prophylaxis: Timing and Duration Do Matter. JAMA Surgery. 2019;154(7):598-9. Doi: 10.1001/jamasurg.2019.0570

66. Nakwatumbah S, Kibuule D, Godman B, Haakuria V, Kalemeera F, Baker A, et al. Compliance to guidelines for the prescribing of antibiotics in acute 
infections at Namibia's national referral hospital: a pilot study and the implications. Expert Review of Anti-infective Therapy. 2017;15(7):713-21. Doi: $10.1080 / 14787210.2017 .1320220$

67. Arulappen AL, Danial M, Haron N, Hau LC, Khan AH. The Impact of Antimicrobial Stewardship Program on Injudicious Use of Cefuroxime. Frontiers in Pharmacology. 2021;11(1944). Doi: 10.3389/ fphar.2020.565818

68. Olaru ID, Meierkord A, Godman B, Ngwenya C, Fitzgerald F, Dondo V, et al. Assessment of antimicrobial use and prescribing practices among pediatric inpatients in Zimbabwe. Journal of Chemotherapy. 2020: 32(8): 456-9. Doi: 10.1080/1120009X.2020.1734719

69. Niaz Q, Godman B, Campbell S, Kibuule D. Compliance to prescribing guidelines among public health care facilities in Namibia; findings and implications. International Journal of Clinical Pharmacy. 2020;42(4):1227-36. Doi: 10.1007/s11096-020-01056-7

70. Eriksen J, Gustafsson LL, Ateva K, Bastholm-Rahmner P, Ovesjo ML, Jirlow M, et al. High adherence to the 'Wise List' treatment recommendations in Stockholm: a 15-year retrospective review of a multifaceted approach promoting rational use of medicines. BMJ Open. 2017;7(4):e014345. Doi:10.1136/bmjopen-2016-014345

71. Godman B. Ongoing initiatives to improve the prescribing of medicines across sectors and the implications. Adv Hum Biol. 2020; 10 (3): 85-9 Doi: 10.4103/AIHB.AIHB 9020

72. Kalaba M, Kosutic J, Godman B, Radonjic V, Vujic A, Jankovic S, et al. Experience with developing antibiotic stewardship programs in Serbia: potential model for other Balkan countries? Journal of Comparative Effectiveness Research. 2018;7(3):247-58. Doi: 10.2217/cer-20170055

73. Sharland M, Gandra S, Huttner B, Moja L, Pulcini C, Zeng $\mathrm{M}$, et al. Encouraging AWaRe-ness and discouraging inappropriate antibiotic use-the new 2019 Essential Medicines List becomes a global antibiotic stewardship tool. The Lancet Infectious Diseases. 2019;19(12):127880. Doi: 10.1016/S1473-3099(19)30532-8

74. Hsia Y, Lee BR, Versporten A, Yang Y, Bielicki J, Jackson C, et al. Use of the WHO Access, Watch, and Reserve classification to define patterns of hospital antibiotic use (AWaRe): an analysis of paediatric survey data from 56 countries. The Lancet Global Health. 2019;7(7):e861-e71. Doi: 10.1016/S2214109X(19)30071-3

75. van den Bosch CM, Hulscher ME, Akkermans RP, Wille J, Geerlings SE, Prins JM. Appropriate antibiotic use reduces length of hospital stay. The Journal of Antimicrobial Chemotherapy. 2017;72(3):923-32. Doi: $10.1093 / \mathrm{jac} / \mathrm{dkw} 469$
76. Ahmed SA, Kumar A, Sethi P, Kapil A, Pandey RM, Wig N. Effectiveness of education and antibiotic control programme at All India Institute of Medical Sciences, New Delhi. The National Medical Journal of India. 2018;31(5):262-7. Doi: 10.4103/0970-258X.261176.

77. Shrayteh ZM, Rahal MK, Malaeb DN. Practice of switch from intravenous to oral antibiotics. Springerplus. 2014;3:717. Doi: 10.1186/2193-1801-3-717

78. Campbell SM, Godman B, Diogene E, Furst J, Gustafsson LL, MacBride-Stewart S, et al. Quality indicators as a tool in improving the introduction of new medicines. Basic \& Clinical Pharmacology \& Toxicology. 2015;116(2):14657. Doi: 10.1111/bcpt.12295

79. Campbell SM, Kontopantelis E, Hannon K, Burke M, Barber A, Lester HE. Framework and indicator testing protocol for developing and piloting quality indicators for the UK quality and outcomes framework. BMC Fam Pract. 2011;12:85. Doi: 10.1186/1471-2296-12-85

80. Storr J, Twyman A, Zingg W, Damani N, Kilpatrick C, Reilly J, et al. Core components for effective infection prevention and control programmes: new WHO evidence-based recommendations. Antimicrob Resist Infect Control. 2017;6:6. Doi: 10.1186/s13756-0160149-9

81. Mpinda-Joseph P, Anand Paramadhas BD, Reyes G, Maruatona MB, Chise M, Monokwane-Thupiso BB, et al. Healthcare-associated infections including neonatal bloodstream infections in a leading tertiary hospital in Botswana. Hospital Practice. 2019;47(4):203-10. Doi: 10.1080/21548331.2019.1650608

82. Cooper L, Sneddon J, Afriyie DK, Sefah IA, Kurdi A, Godman B, et al. Supporting global antimicrobial stewardship: antibiotic prophylaxis for the prevention of surgical site infection in low- and middle-income countries (LMICs): a scoping review and meta-analysis. JAC-Antimicrobial Resistance. 2020;2(3). Doi:10.1093/ jacamr/dlaa070

83. Donà $\mathrm{D}$, Barbieri E, Daverio $\mathrm{M}$, Lundin $\mathrm{R}$, Giaquinto $\mathrm{C}$, Zaoutis $\mathrm{T}$, et al. Implementation and impact of pediatric antimicrobial stewardship programs: a systematic scoping review. Antimicrob Resist Infect Control. 2020;9(1):3. Doi: 10.1186/s13756-019-0659-3

84. Nathwani D, Varghese D, Stephens J, Ansari W, Martin $\mathrm{S}$, Charbonneau C. Value of hospital antimicrobial stewardship programs [ASPs]: a systematic review. Antimicrobial Resistance and Infection Control. 2019;8:35-. Doi: 10.1186/s13756-019-0471-0

85. Gitaka J, Kamita M, Mureithi D, Ndegwa D, Masika M, Omuse G, et al. Combating antibiotic resistance using guidelines and enhanced stewardship in Kenya: a protocol for an implementation science approach. BMJ Open. 2020;10(3):e030823. Doi:10.1136/ bmjopen-2019-030823 
86. Engler D, Meyer JC, Schellack N, Kurdi A, Godman B. Compliance with South Africa's Antimicrobial Resistance National Strategy Framework: are we there yet? Journal of Chemotherapy. 2021;33(1):21-31. Doi: 10.1080/1120009X.2020.1789389

87. Schellack N, Bronkhorst E, Coetzee R, Godman B, Gous AGS, Kolman S et al. SASOCP position statement on the pharmacist's role in antibiotic stewardship 2018. South African Journal of Infectious Disease. 2018;33(1):2835.

88. Chigome AK, Matlala M, Godman B, Meyer JC. Availability and Use of Therapeutic Interchange Policies in Managing Antimicrobial Shortages among South African Public Sector Hospitals; Findings and Implications. Antibiotics. 2019;9(1). Doi:10.3390/ antibiotics 9010004

89. Acosta A, Vanegas EP, Rovira J, Godman B, Bochenek T. Medicine Shortages: Gaps Between Countries and Global Perspectives. Frontiers in Pharmacology. 2019;10:763. Doi: 10.3389/fphar.2019.00763

90. Government of the People's Republic of Bangladesh Ministry of Health and Family Welfare. Guideline for Model Pharmacy. 2016. Available at URL: http://dgda. gov.bd/index.php/2013-03-31-05-16-29/guidancedocuments/175-guideline-for-model-pharmacy?path=. (Accessed 25 February 2021)

91. UKEssays. Pharmacy Education in Bangladesh. November 2018. Available at URL: https://www.ukessays.com/ essays/health/pharmacy-education-bangladesh-9594. php?vref=1. (Accessed 25 February 2021)

92. WHO. WHO discontinues hydroxychloroquine and lopinavir/ritonavir treatment arms for COVID-19. 4 July 2020. Available at URL: https://www.who.int/ news-room/detail/04-07-2020-who-discontinues- hydroxychloroquine-and-lopinavir-ritonavir-treatmentarms-for-covid-19. (Accessed 25 February 2021)

93. Horby P, Mafham M, Linsell L, Bell JL, Staplin N, Emberson JR, et al. Effect of Hydroxychloroquine in Hospitalized Patients with Covid-19. $N$ Engl J Med. 2020;383(21):2030-40. Doi: 10.1056/NEJMoa2022926

94. Abena PM, Decloedt EH, Bottieau E, Suleman F, Adejumo P, Sam-Agudu NA, et al. Chloroquine and Hydroxychloroquine for the Prevention or Treatment of COVID-19 in Africa: Caution for Inappropriate Offlabel Use in Healthcare Settings. Am J Trop Med Hyg. 2020;102(6):1184-8. Doi: 10.4269/ajtmh.20-0290

95. Ferner RE, Aronson JK. Chloroquine and hydroxychloroquine in covid-19. BMJ. 2020;369:m1432. Doi: 10.1136/bmj.m1432

96. Godman B. Combating COVID-19: Lessons learnt particularly among developing countries and the implications. Bangladesh Journal of Medical Science, Special Issue on Covid19. 2020; S103-8. Doi: https:// doi.org/10.3329/bjms.v19i0.48413. Doi: 10.3329/bjms. v19i0.48413

97. Recovery Collaborative Group. Lopinavir-ritonavir in patients admitted to hospital with COVID-19 (RECOVERY): a randomised, controlled, open-label, platform trial. Lancet. 2020;396(10259):1345-52. Doi: 10.1016/S0140-6736(20)32013-4

98. Dyer O. Covid-19: Remdesivir has little or no impact on survival, WHO trial shows. BMJ. 2020;371:m4057. Doi: 10.1136/bmj.m4057 